\title{
Commentary: Tissue valves in younger patients: Hazardous developments on the horizon
}

\author{
Paul Philipp Heinisch, MD, and Thierry Carrel, MD
}

\footnotetext{
From the Department of Cardiovascular Surgery, Inselspital, University Hospital, University of Bern, Bern, Switzerland.

Disclosures: Authors have nothing to disclose with regard to commercial support.

Received for publication Dec 13, 2018; accepted for publication Dec 14, 2018; available ahead of print Jan 23, 2019.

Address for reprints: Thierry Carrel, MD, Department of Cardiovascular Surgery, University Hospital and University of Bern, Freiburgstrasse 18, CH - 3010 Berne, Switzerland (E-mail: thierry.carrel@insel.ch).

J Thorac Cardiovasc Surg 2019;158:46-7

$0022-5223 / \$ 36.00$

Copyright (c) 2018 by The American Association for Thoracic Surgery

https://doi.org/10.1016/j.jtcvs.2018.12.038
}

Since the first transcatheter aortic valve implantation (TAVI) 15 years ago, this technology with explosive potential represents among the major medical breakthroughs of the past decade. ${ }^{1}$ The expansion of TAVI was considerable, thanks to continuous refinements in valve technology, delivery systems, and procedure techniques, leading to dramatically improved clinical outcomes. TAVI is on the way to becoming (if it is not already) the default strategy for the treatment of aortic stenosis, even in younger patients. Additionally, the development of valve-in-valve TAVI has opened a new frontier for the treatment of failing tissue valves after surgical aortic valve replacement (SAVR) due to structural valve deterioration. ${ }^{2}$ The evolution of transcatheter technologies is underway to induce a tremendous threshold shift toward the implantation of tissue valves in patients younger than age 60 years followed by valve-invalve TAVI before receiving — perhaps — a final SAVR later in life when no more interventional options are available. Although this might appear reasonable in high-risk and elderly patients, this approach is not supported by scientific evidence in younger patients, especially not for those without comorbidities or contraindication for anticoagulation. $^{3}$ The trend toward implantation of tissue valves in younger patients is a hazardous development on the horizon. The long-term durability of the tissue valves in younger patients is largely unanswered without any evidence regarding significantly lower long-term mortality. On the other side, the latest mechanical aortic valves significantly reduced risk of bleeding without a significant increase in thromboembolic complications at an international normalized ratio target range of 1.5 to $2.0 .{ }^{4}$ Nowadays, there is increasing controversy regarding the best choice of valve for patients younger than age 60 years: mechanical or biological?

Ranganath and colleagues ${ }^{5}$ present a new methodical analysis by using microsimulation models to understand lifetime risks of aortic valve re-replacement in younger patients (aged younger than 60 years). These models incorporate changing hazards to estimate the risk of re-replacement

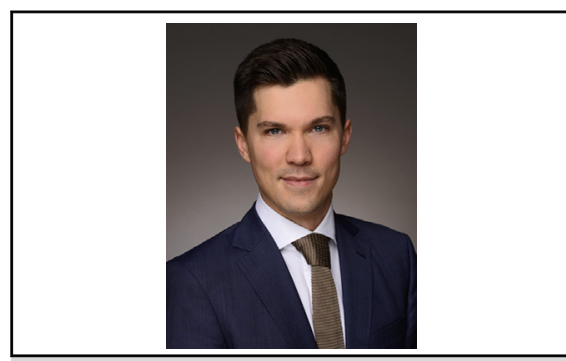

Procedural algorithm for patients younger than age 60 years who are scheduled for aortic valve replacement.

Central Message

Patients younger than age 60 years without comorbidities or contraindication to oral anticoagulation therapy should receive a mechanical valve when the aortic valve has to be replaced.

See Article page 39.

and mortality from re-replacement in patients undergoing tissue SAVR. The group concluded that younger patients have a significant risk of requiring an aortic valve re-replacement or even multiple re-replacements. Approximately $57 \%$ of 50 -year-old patients receiving a primary tissue SAVR would require a second valve in his or her lifetime and about $18 \%$ at least 1 additional (ie, a third) valve after that re-replacement. Furthermore, according to the analysis, a sobering fact is that $13.1 \%$ of those patients would require their first re- replacement within only 10 years of the primary SAVR. However, despite the significant risk of re-replacements, overall median life expectancy for a 50-year-old patient receiving primary tissue SAVR was only 0.3 years less than ageand sex-matched controls, indicating that operative mortality for re-replacements is not a major cause of death after primary tissue SAVR.

There are some limitations to the predictions analyzed from the microsimulation models:

- The authors only relied on 1 study to obtain the estimates for the rates of SVD causes for reoperation and only 1 type of tissue valve. Therefore, as the authors mention, this represents a best-case scenario because it utilizes the most optimistic tissue valve longevity data and assumes patients do not have any major comorbidities. ${ }^{6}$ 
- Furthermore, the study data used for microsimulation models only considered implanted tissue valves in patients younger than age 60 years if the patient had a poor life expectancy, endocarditis, or a contraindication to anticoagulation therapy. As such, rates of valve durability may not represent those of the healthy population used for the simulation. This bias is important when evaluating the validity of the results and accuracy of estimations.

- Tissue valve durability is influenced by type (eg, sutureless or stentless); size; effective orifice area; and, as a consequence, transvalvular pressure gradients. ${ }^{7}$ These factors were not considered in the microsimulation analysis and therefore the results cannot be extrapolated to other types of tissue valves.

The authors raise an interesting question: Should we be exposing younger patients to the risk of multiple aortic valve re-interventions to avoid the risks associated with a therapeutic international normalized ratio of 1.8 ?

Valve selection is always a balanced decision, considering the pros and cons of both types of prostheses: the limited durability of tissue valves and the lifelong requirement for anticoagulation with subsequent increased risk of bleeding and thromboembolic complications after mechanical valve replacement. Furthermore, the selection of the prosthesis depends on various patient-related factors, such as age at implantation and therefore the remaining life expectancy, durability of the valve, compliance with long-term anticoagulation, and patient preferences. Although the current study cannot provide a conclusive recommendation for the selection of valves in younger patients, it is clearly a sophisticated method for a prospective analysis of the rate of rereplacement of tissue SAVR, especially due to the ability of the model to account for changing hazards.
A systematic review applying propensity matching for the analysis of mechanical versus tissue valves found either similar outcomes between the tissue and mechanical valves or favorable outcomes with mechanical valves, particularly in younger patients. ${ }^{8}$

There is currently no evidence to support lowering the age threshold to justify the implantation of a tissue valve in patients younger than age 60 years. Doctors and patients should be cautious in pursuing more recommendations for tissue valve implantation in younger patients until there is enough evidence to support such a strategy.

\section{References}

1. Cribier A, Eltchaninoff H, Tron C, Bauer F, Agatiello C, Sebagh L, et al. Early experience with percutaneous transcatheter implantation of heart valve prosthesis for the treatment of end-stage inoperable patients with calcific aortic stenosis. J Am Coll Cardiol. 2004;43:698-703.

2. Erlebach M, Wottke M, Deutsch M-A, Krane M, Piazza N, Lange R, et al. Redo aortic valve surgery versus transcatheter valve-in-valve implantation for failing surgical bioprosthetic valves: consecutive patients in a single-center setting. J Thorac Dis. 2015;7:1494-500.

3. Reineke DC, Heinisch PP, Winkler B, Englberger L, Carrel TP. Mitral valve replacement in patients under 65 years of age: mechanical or biological valves? Curr Opin Cardiol. 2015;30:146-50.

4. Puskas J, Gerdisch M, Nichols D, Quinn R, Anderson C, Rhenman B, et al Reduced anticoagulation after mechanical aortic valve replacement: interim results from the prospective randomized on- $\mathrm{X}$ valve anticoagulation clinical trial randomized Food and Drug Administration investigational device exemption trial. J Thorac Cardiovasc Surg. 2014;147:1202-10.

5. Ranganath NK, Koeckert MS, Smith DE, Hisamoto K, Loulmet DF, Galloway AC et al. Aggressive tissue aortic valve replacement in younger patients and the risk of re-replacement: implications from microsimulation analysis. J Thorac Cardiovasc Surg. 2019;158:39-45.

6. Bourguignon T, El-Khoury R, Candolfi P, Loardi C, Mirza A, BoulangerLothion J, et al. Very long-term outcomes of the Carpentier-Edwards Perimount Aortic Valve in patients aged 60 or younger. Ann Thorac Surg. 2015;100:853-9.

7. Johnston DR, Soltesz EG, Vakil N, Rajeswaran J, Roselli EE, Sabik JF, et al. Long term durability of bioprosthetic aortic valves: implications from 12,569 implants. Ann Thorac Surg. 2015;99:1239-47.

8. Head SJ, Çelik M, Kappetein AP. Mechanical versus bioprosthetic aortic valve replacement. Eur Heart J. 2017;38:2183-91. 